Thus far the method has produced no untoward effects. Eleven animals have been so treated and none have shown any ill results from the injections per se. The attenuated material of the first three injections has apparently produced sufficient immunity to render the animal resistant to the subsequent injections of virus of high virulence.

That this is so was proved by results in four other animats, two of which were injected subcutaneously with crude virus thought to be attenuated by exposure to a weak formaldehyd solution, and two that were injected subcutaneously with virus heated to $50 \mathrm{C}$. for one-half hour. All of these animals developed poliomyelitis as a result of the subcutaneous injections.

The possibility of harmful effects from the method if applied to human beings is, of necessity, less than when applied to monkeys, since this virus has been adapted to monkeys for the past eight years, and by constant passage through these animals has become highly virulent for the monkey.

The period required for this series of injections is a short one, only five days, which, of course, would render it highly practicable in time of epidemic, when a rapid method is to be desired. Furthermore, it is a simple method. Ordinary laboratory facilities are sufficient for the production of this vaccine. Glycerolated brains and cords of this highly virulent virus can be kept on hand over long periods of time, and the vaccine made up from time to time from this stock as occasion demands.

Further work along these lines is in progress, particularly with reference to the duration of the period of immunity conferred by this method.

\section{THE VALUE OF ROENTGEN RAYS AND BENZENE IN THE TREATMENT OF POLYCYTHEMIA VERA *}

\author{
SAMUEL H. HURWITZ, M.D. \\ AND \\ ERNEST H. FALCONER, M.D. \\ SAN FRANCISCO
}

The treatment of that form of polycythemia associated with splenomegaly and chronic cyanosis has not, up to the present time, been entirely successful. In the absence of any exact knowledge concerning the pathology of polycythemia vera, therapeutists have been unable to attack the disease at its source. The treatment has, for the most part, been symptomatic, and the available therapeutic measures have been directed chiefly to the reduction in the number of circulating red blood corpuscles. Such efforts have been well directed, because it seems not unlikely that many of the symptoms of the disease-the headache, vertigo, cyanosis and dyspnea-are in great part attributable to the mechanical stasis in the circulation due to the polyglobulism. And whereas, the therapentic agents employed have not resulted in permanent cures, they have been effective in reducing the number of circulating erythrocytes, and on this account they merit the attention that has been accorded them.

With this end in view, a number of methods have been tried, such as splenectomy, venesection, the

* From the Medical Clinic, University of California Hospital.

* Presented before the meeting of the San Francisco County Medical Society, Feb. 12, 1918. administration of drugs, and the application of various rays either to the spleen or to the long bones.

The removal of the spleen in this disease has usually been fatal within a few days, and the treatment is therefore contraindicated.

Venesection has been employed on the ground that it gives at least temporary relief. But all who have resorted to this measure are now agreed that even if repeated at fairly regular intervals, venesection fails to produce any permanent good effects.

The drug therapy of this affection has been especially inclusive, as nitrites, iodids, bromids, mercury, and a host of other medicinal agents have all been tried. With the exception of benzene (benzol, $\mathrm{C}_{6} \mathrm{H}_{6}$ ), however, these drugs have brought about only a doubtful improvement in the clinical symptoms of which these patients complain.

The results reported from the use of the roentgen rays alone are contradictory. Judging from the observations recorded in the literature, the application of roentgen rays has been of marked benefit in some cases, whereas their employment has been unsuccessful in others.

It is our purpose in this report to record the beneficial therapeutic results that have followed the combined use of benzene and roentgen rays in a patient presenting the classical signs and symptoms of polycythemia vera. Although more than a year has elapsed since any form of treatment has been given, the patient's blood still shows a normal number of red blood corpuscles and a normal hemoglobin percentage. Her health continues excellent. The headache and dizziness, symptoms which first brought her under medical observation, have entirely disappeared. There has been an almost complete disappearance of the cyanosis of the facial prominences and extremities, although the lips and mucous membranes still have a reddish cyanotic hue. The improvement in her psychic condition has been marked since she has ceased to be a subject of general interest and curiosity.

\section{REPORT OF CASE}

M. D., aged 38, a milliner by occupation, first came under medical observation in April, 1915, complaining of nervousness and dizziness. There had been little illness in her family, and she herself had always been in excellent health. Aside from measles and diphtheria in childhood, she could recall no periods of ill health.

About three or four years before she was first seen, she had had a sudden attack of dizziness lasting only a few minutes, followed by occasional headaches, and in April, 1915, she had been suddenly seized with an attack of blindness, lasting fifteen or twenty minutes.

It was after this last attack that she was examined by Dr. E. H. Julien, who had noted considerable cyanosis of the face, gums, arms and hands. May 18, 1915, a blood count was made which showed a hemoglobin percentage of 105 , $12,400,000$ red blood corpuscles, and 9,000 white blood corpuscles. A diagnosis of polycythemia vera was made and the patient entered a hospital for treatment. This consisted of a milk diet, frequent intramuscular injections of an arsenical preparation, and venesection. For a period of more than a year, from June, 1915, to August, 1916, venesection was the principal mode of treatment, and she remained comparatively free from subjective symptoms during this period.

In July, 1916, the patient first came under our care. ${ }^{1}$ She was found to be well developed and very well nourished, with a dark red face, cyanotic cheeks, and with lips and gums

1. For the opportunity of following the patient subseguently and for the privilege of carrying out the form of treatment outlined in this patient to us. 
also of a somewhat brick red, cyanotic hue. The pupils were dilated, showed a regular outline, and reacted to light and direction. The fundi showed no abnormalities. The teeth were in good condition and the tongue was dark red. The thyroid was not increased in size, and there was no general glandular enlargement. Both heart and lungs were normal. The abdomen was full, rounded and symmetrical. The spleen could be palpated about a hand's breadth below the costal border; the edge was rounded, smooth and slightly tender. The edge of the liver could not be felt, nor were the kidneys palpable. Both upper and lower extremities showed a marked grade of cyanosis. All the reflexes were normal. The Wassermann reaction of the blood serum was negative. The urine was of a dark amber, its specific gravity was 1.020 , and reither albumin nor sugar was present. No casts were found. An occasional red blood corpuscle and a few white blood cells were present.

A venesection was done, July 20 , and 500 c.c. of blood were removed. The patient was given iodids for a week. August 2, roentgen-ray treatment was begun. ${ }^{2}$

Oct. 9, 1916, she was admitted to the medical service of the University of California Hospital, where she remained for two weeks. The general findings on physical examination were for the most part the same. The skin was still of a high color, with a cyanotic tinge over the cheeks, malar eminences, nose and ears. The spleen was felt $5 \mathrm{~cm}$. below the costal border, and the splenic dulness extended $15 \mathrm{~cm}$. upward. The edge was firm, but not tender.

An electrocardiogram of the heart showed normal rhythm. The total nonprotein nitrogen of the blood was $43.9 \mathrm{mg}$. per

2. We are indebted to Dr. Howard E. Ruggles for the supervision over the roentgen-ray treatments. hundred c.c, and the urea nitrogen was found to be 14 mg. + , both being normal. The percentage volume of carbon dioxid in the blood (Van Slyke) was 52.5, normal.

During her stay in the hospita1, the patient took $33 \mathrm{gm}$. of benzene in one week. This was administered in capsules with equal parts of olive oil. A little less than $5 \mathrm{gm}$. per day was given. The patient complained of no untoward gastric symptoms from the drug.

After her discharge from the hospital, she took $8.5 \mathrm{gm}$, of benzene from November 10 to 18 , when administration of the drug had to be discontinued on account of a burning sensation in the stomach, with regurgitation and belching. A further attempt to continue the drug was made from November 23 to 28 , when the patient ingested 3 additional grams of benzene. The drug now had to be stopped permanently on account of nausea, gastric discomfort and headaches.

The only other form of treatment from September to November consisted of two roentgen-ray exposures over the spleen, one of 25 milliampere minutes, and the second of 30 milliampere minutes. These were continued in December and January, five additional exposures of the spleen having been made during this interval. The results of the treatment are set forth in the accompanying table.

The patient was observed at frequent intervals until May, 1917. By the end of January, 1917, the blood picture showed a complete return to normal, the red count being $5,200,000$ and the white blood corpuscles 9,200, with a hemoglobin percentage of 98 . The patient's subjective symptoms had entirely disappeared, and the objective signs of the disease were decidedly less pronounced. The skin and mucous membranes were still somewhat suffused, but they were definitely less bluish, whereas the cyanosis and lividness of the extremities

EFFECT OF ROENTGEN RAYS AND BENZENE ON THE RLOOD IN POLYCYTHEMIA

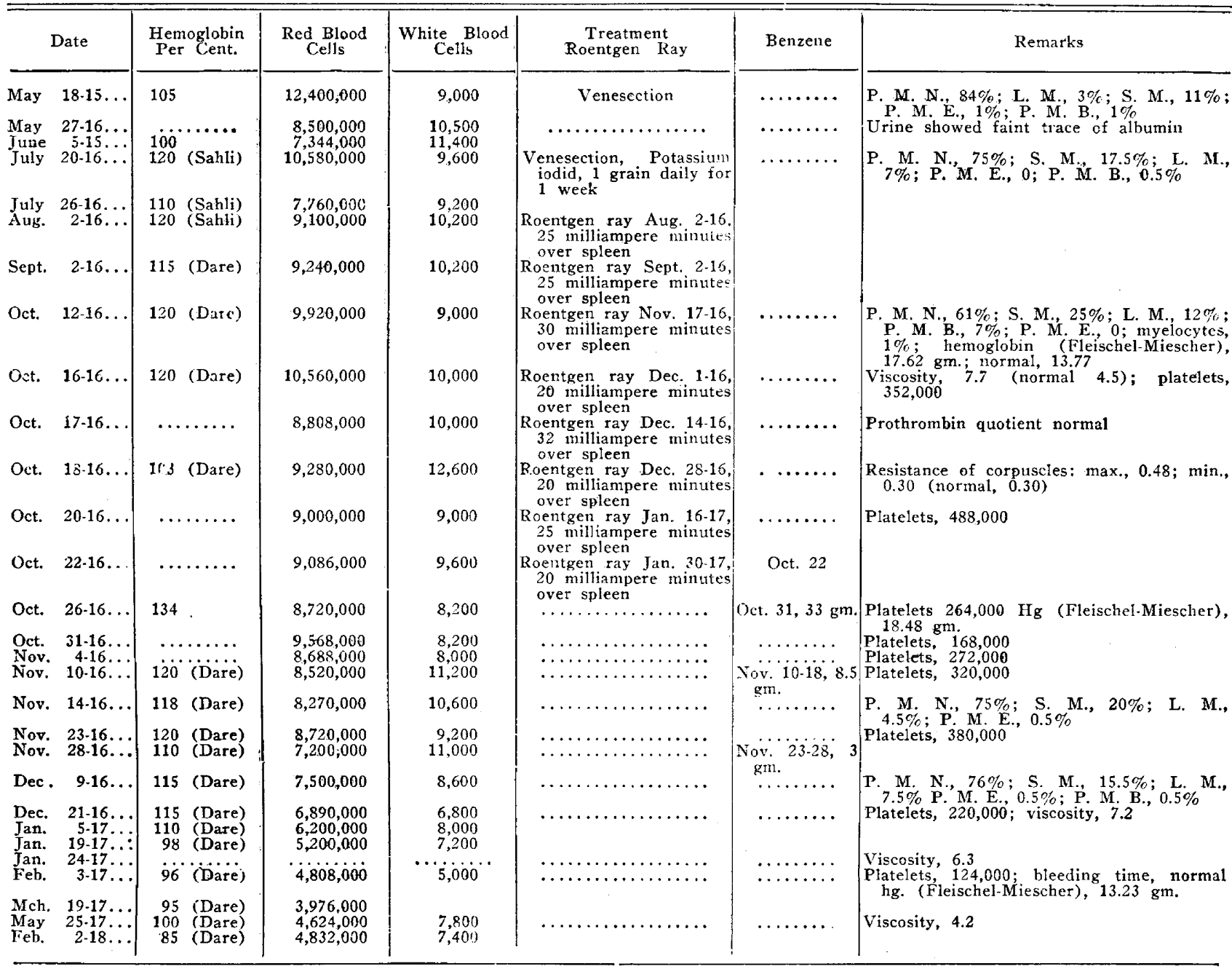


had entirely disappeared. At this time, the spleen had com. pletely receded above the costal margin and could no longer be palpated.

When last seen in February, 1918, about sixteen months after the beginning of the benzene and roentgen-ray treatment, the patient still continued well, in spite of the fact that no form of treatment had been given during this period, and the number of red blood corpuscles and the percentage of hemoglobin remained within normal limits.

\section{COMMENT}

Experimental and clinical observations concerning the effect of drugs and various radioactive substances on the blood and blood-forming organs have brought forth some interesting facts regarding the relative resistance to these agents offered by the white blood cells and the red blood corpuscles. In the first instance it has been shown that the various drugs and rays employed exert a selective action on the several tissues giving origin to the formed elements of the blood; and secondly, that the leukopoietic tissues are much less resistant to their destructive action than are the tissues concerned with the formation of erythrocytes. The latter elements, it would appear, show only moderate changes in number and structure at a time when the circulating leukocytes may have almost completely disappeared from the circulation.

The observations of Heinecke and of Selling have established these facts, so far as the action of the roentgen rays or of benzene is concerned. This work shows that the roentgen rays exert a selective action on the lymphocytes, and that even prolonged irradiation will not bring about any noteworthy changes either in the number of red blood corpuscles or in the percentage of hemoglobin. Benzene, on the contrary, has a somewhat different action. This drug has been shown by Selling to act destructively first on the white cells and more especially on the nongranular elements, and later to cause a diminution in the number of erythrocytes. The experimental studies have shown, however, that in order to effect any striking anemia, the drug must be administered in large doses and over a long period of time.

It is because of this essential lymphotoxic action that the roentgen rays alone have not been found of great value in the treatment of polycythemia. Whereas benzene, on the other hand, has yielded some brilliant results in the treatment of this disease, it must be kept in mind that these good effects have usually followed the prolonged ingestion of large doses of the drug--a procedure not entirely without danger. The danger lies, first, in the severe gastro-intestinal disturbance which may follow the administration of very large doses, and secondly, in the marked destructive action which these large amounts may have on the circulating leukocytes.

It was with the hope of testing the value of smaller amounts of benzene, when combined with the roentgen rays, that the mode of treatment outlined in this paper was carried out. The patient, as will be noted from the clinical record and the table, received only $44 \mathrm{gm}$. of the drug within a period of a month, after which the benzene was stopped. The roentgen-ray treatments, however, were continued about two months longer. Although considerable reduction in the red count followed the use of benzene alone, the erythrocytes began to approach the normal level only after the seventh roentgen-ray treatment.

The good effects of the combined treatment may be attributed either to the joint action of both measures, or to the delayed and cumulative action of the benzene itself. It does not appear likely that the latter measure can be the cause, since previous observers did not succeed in reducing the red count appreciably with the amount of benzene administered to our patient. We are, therefore, inclined to attribute this successful therapeutic result to the combined action of both agents. But the manner in which the roentgen rays may have served as an adjuvant to benzene therapy in this instance is not quite clear. We would venture the suggestion, however, that the roentgen rays may act in a more destructive manner on erythropoietic tissues, which have been rendered less resistant beforehand by the toxic action of benzene.

Second and Parnassus Avenues.

\section{Clinical Notes, Suggestions, and New Instruments}

\section{A SELF-FILLING HYPODERMIC SYRINGE}

\section{A. N. Bessesen, M.D., Minneapolis}

Local anesthesia is growing in popularity with the medical profession. Generally we have to rely on the ordinary hypodermic syringe for the application of the anesthesia, unless one is fortunate enough to own a Farr apparatus. In the use of the ordinary syringe much time is consumed in refilling, or even in the exchange of syringes. It was with the thought of avoiding this delay that $I$ devised the syringe illustrated.

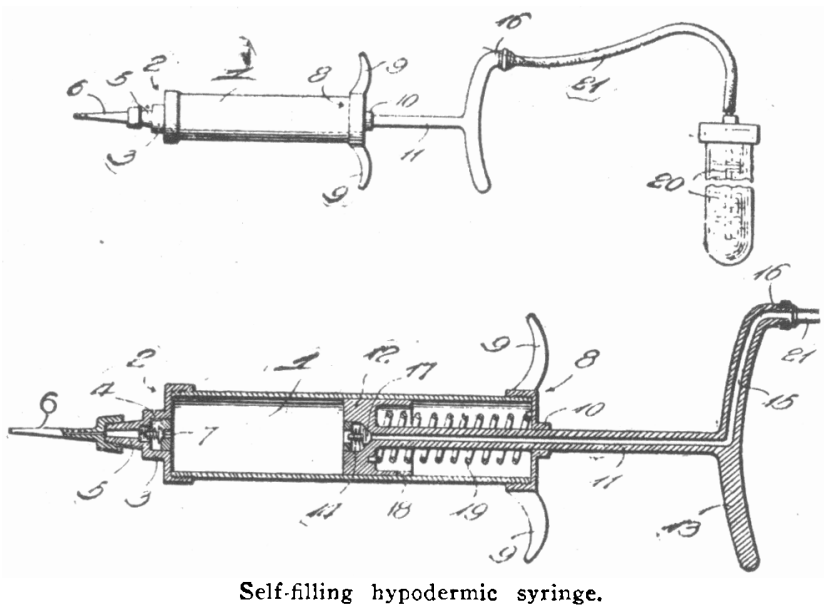

The syringe refills itself from a container attached to the syringe and suspended conveniently from the wrist of the surgeon. In this way a small or large amount of the anesthetic may be injected accurately with the least effort. In the illustration, 7 and 17 indicate the outlet and inlet valves, 11,15 and 16 the intake channel, and 20 the container for the supply fluid.

RUPTURE OF DEEP EPIGASTRIC ARTERY BY MUSCULAR STRAIN: REPORT OF A CASE

Mark Lewis Emerson, M.D., Oakland, Calif.

History.-A housewife, white, aged 42 , with four living children, had had seven miscarriages, five of which had occurred between the third and fifth month, and two during the seventh month. She was admitted to the Merritt Hospital at 9:30 p. m., Sept. 8, 1917, and discharged as cured, November 10 . The patient stated that about $5: 30 \mathrm{p} . \mathrm{m}$. on the day of admission, four hours before reaching the hospital, while trying to place a curtain rod over a window bracket, 